\title{
The Occupational Dimensions of Local Labour Markets in Australian Cities
}

\author{
Anthea Bill, Bill Mitchell and Martin Watts, \\ Centre of Full Employment and Equity (CofFEE), University of Newcastle.
}

\begin{abstract}
It has been argued that declining housing affordability in Australia's major cities has led to the exclusion of some low and moderate income residents from high employment, innercity regions. If there is an increasing spatial mismatch between housing and employment, moderately paid workers, essential to the efficient functioning of the urban economy, may face problems in accessing and retaining employment. However to date there has been a lack of empirical analysis of the overlap between spatial dimensions of housing and employment (and the commuting such divisions necessitate) broken down by occupation.
\end{abstract}

Using the 2001 Census Journey to Work data, broken down by occupation, we employ a range of analytic techniques to examine local labour markets in Sydney, Melbourne and Brisbane. Firstly we develop formal commuting areas which represent local labour markets. Secondly, we examine self-average commutes and self-containment ratios for occupational groups across the metropolitan local labour markets. Secondly, linear programming techniques are employed to examine the nature of commuting, given the complex locational decisions made by residents. Results reveal some variation in commuting patterns across occupations with little variation in commutes but higher self-containment ratios at the SLA level for some lowskilled occupations. However longer commutes are found amongst low-skill occupations after controlling for the 'excess' or volitional nature of commuting, and suggests the distribution of jobs given the distribution of residents is more unequal for low-skill occupations. High skilloccupations tend to display higher rates of excess commuting reflecting that factors other than job-proximity may be influencing their locational decisions.

\section{Introduction}

A wide range of factors, including housing affordability, proximity to work and amenities, as well as childcare, schools, recreational facilities and shopping, and access to the extended family and friends, impact on the interdependent decisions made by individuals (and households) about employment and housing location. The availability of both private and public forms of transportation influence the potential distance commuted, with the former linked to the availability of sufficient household income and hence job opportunities.

Much evidence points to the intensification of the spatial polarisation of housing and employment and associated declining housing affordability within Australia's major cities, particularly Sydney. In turn it has been argued, both here and overseas, that growing inner-city skill shortages (see DEST, 2002; Nelson, 2004) reflect the way house price appreciation has worked to exclude low and moderate income residents from high employment, inner-city regions. Longer commutes faced by lower and moderate income workers who choose to live where housing is affordable (in the outer suburbs), act as a deterrent to employment, and are said to impose costs on employers: in the form of higher staff turnover, lengthy recruitment periods to find replacement staff, and extra costs associated with training of staff (Yates,2005:18). Berry (2006:iii) argues "in effect, urban housing and labour markets may be inefficiently articulated over space with consequences of shortages and recruitment difficulties in some lower paid but functionally necessary occupations and/or higher wages to offset high housing costs or more expensive commuting. In the latter context, a series of negative second-order externality effects may arise due to the sharp rise in car dependence commuting." In short, are housing markets pricing low and moderate income workers out of job rich areas?

Our analysis revisits this question for all occupations, at the 2-digit Australian Standard Classification of Occupations (ASCO) level, and explores patterns of commuting for Statistical Local Areas (SLAs) in Sydney, Melbourne and Brisbane. The available data does not allow us to isolate those public sector employees indicated in the 'key worker' debate and so we turn our analysis to a broader examination of occupational differences in commuting. We employ significant advances on previous approaches through the adoption of a coherent methodology for the formal analysis of commuting patterns within self contained regions of Sydney, Melbourne and Brisbane. We firstly construct commuting areas - that is we adopt a formal approach to defining the metropolitan labour market in a statistical sense, based on self- 
containment. Having defined the metropolitan 'commuting areas' for Australia's three largest cities, where most workers live and work, we examine commuting distances and self-containment rates for one and two digit ASCO occupations. Furthermore we draw on US literature to explore the nature of commuting by occupation in Sydney, Melbourne and Brisbane. We separate out the 'morphological' and 'behavioural' components of commuting (Charron, 2007) in light of the finding that changes in the housing market may be placing stress on journey to work, for occupations (at the 1-digit level) in each of the capital cities. Preliminary analysis of average commutes and self-containment ratios reveal little variation in commuting patterns across occupations but higher self-containment ratios are revealed at the SLA level for low-skill occupations. Overall this lends support to Yates (2005) and Yates et al., (2006) who find little evidence that low-skill occupations have lower levels of employment accessibility. However separating the 'morphological' and 'behavioural' component - longer commutes are found amongst low-skill occupations after controlling for the 'excess' or volitional nature of commuting (after normalization). This suggests the distribution of jobs given the distribution of residents is more unequal for low-skill workers. High skilloccupations tend to display higher rates of excess commuting reflecting that factors other than jobproximity may be influencing their locational decisions. The paper is structured as follows: Section 2 reviews the current literature, Section 3 outlines data and methodology, Section 4 reports results and Section 5 concludes.

\section{Literature Review}

Sassen and other urban theorists argue that growing concentrations of advanced business services and other knowledge-intensive jobs in large urban centres, separate global cities from non-global cities 'with respect to size, function, influence and prosperity'. (Berry, 2006:7). Related theories of spatial polarisation (and the Divided City Hypothesis, see Fainstein (1992)) argue that new economy processes have driven occupational polarisation and created pervasive patterns of spatial differentiation within cities. Not only is demand for high skill and high wage employment increasing, but demand for low skill and low wage workers is also increasing. Earlier work by Baum (1997) documents these patterns inside Sydney showing that shifts in the occupational structure of cities have resulted in the growth of high paid professionals and low-paid service workers. A third sector is also identified, namely persons without access to paid work. Baum (1997: 1900) states that "at one end of the scale there exists a growing group of high-income, highstatus individuals who are strongly attached to the global economy and have benefited from global integration. At the other end, there is both a growing group of workers who have only weak labour market attachment to the global economy (low-paid service workers) and a group of workers who are outside the employed labour force, are dependent on welfare, and have benefited very little from global processes." These workers serve an ancillary function and assist new economy/professional workers within urban centres.

There is some overlap between the key worker hypothesis and the longstanding theoretical and empirical debates relating to 'spatial mismatch'. Spatial mismatch can be concisely defined as frictional unemployment resulting from the lack of spatial congruency between a worker's place of residence and potential place of employment. However mismatch which reflects urban form, in the sense of the spatial pattern of housing and employment, may also be manifest in higher wages or excess commuting, or both, rather than unemployment. Gobillon et al., (2003:21) provide several reasons why housing markets, via increased distance to place of employment, might impact on labour market outcomes. For instance, workers living far away from jobs face reduced frequency and quality of job information, and employers favour locally-based recruiting methods. Secondly financial incentives are insufficient to motivate distant workers to search, because search costs are not compensated by wages. Also differentials in dwelling rents are too great to encourage relocation. Thirdly commuting costs (associated with length of commute) are not compensated by wages, and search remains locally based. Fourthly employers do not perceive a worker who is employed in a distant location as a direct substitute for a worker who is close-by. Lastly inadequate public transport may exacerbate these issues.

While the impact of spatial polarisation of housing prices has typically been viewed as an equity issue, the key worker hypothesis emphasises that the polarisation of house prices has potential impacts on economic efficiency, through the generation of both skill shortages and unemployment (or employment not related to a person's occupation, skills or training). As Berry (2006:vi) notes there has been little research into the spatial mismatch debate in Australia and what has been done is largely anecdotal (some empirical work refuting spatial mismatch in Melbourne, see Dodson, 2005). This directly relates to the scarcity of relevant spatial data at an appropriate level of disaggregation. 
The claim that low income or moderate income workers have had difficulty accessing employment in the city owing to housing constraints and long commutes, has gained increasing traction overseas. In the UK the focus has been on specific public sector occupations, especially in areas with high housing costs and housing price hikes which have had implications for 'recruiting and retaining' teachers, nurses, police and emergency service offices, municipal offices and health care workers. The UK government has referred to these workers as 'key workers', that is workers who are 'employed by the public sector, in a frontline role delivering an essential public service and in a sector where there are serious recruitment and retention problems' (OPDM, 2005c, p.14 quoted in Berry, 2006:v). In London, affordable housing policies have been introduced which require " 50 per cent of all new housing developments to be affordable" (Yates, 2005:19). In the US similar concerns have been raised, with recent research carried out by the Essential Worker Immigration Coalition, Urban Land Institute and National Housing Conference pointing to a shortage of appropriate housing for low and moderate income workers in many large cities (Berry, 2006:iv). In a number of US States, 15 to 25 per cent of all housing developments are required to be affordable (Yates, 2005:19). In Australia, a NSW Department of Housing report defined key workers as "workers who provide a service that contributes to the well being of the community and are unable to afford appropriate accommodation on the open market The definition includes, but is not limited to, hospital workers, teachers, child care workers, police, transport workers or fire fighters". (Yates, 2005:7).

Typically Australian regions display high levels of self-containment, that is, most people live and work in the same region, although over the last two decades residential and commercial gentrification has intensified, pushing low income workers to the fringes of the city (Berry, 2006; Dodson et al., 2006). Decentralisation of value adding jobs has not occurred in the Australian labour market as it has in many cities in the US (Berry, 2006:7).Yates et al., (2006) find high rates of housing stress amongst lower income working households, with hospitality workers experiencing the highest incidence of housing stress and sales assistants recording the greatest numbers in housing stress. However public sector occupations such as police or teachers, which are central to most conceptualisations of the key worker debate, face a below average incidence of affordability problems (Yates et al., 2006:vii). Housing affordability problems are not so much driven by occupation as by low incomes (reflecting underlying wage inequality across occupations) and locational choices. The highest incidence of housing stress is found amongst workers in the Sydney metropolitan region, and in south-eastern Queensland and inner regions of Melbourne (2006:vii).

In the only occupational analysis of journey to work undertaken to date Yates (2005) and Yates et al., (2006) examine commuting patterns to reveal that only some occupations (namely computing professionals) had an increased proportion of workers facing long commutes - because they chose to live further out and their work was more likely to be located in inner city locations. They find that there are high levels of self-containment at a broad regional level within these key metropolitan regions, with approximately half of the workforce living locally (p. ix). Most workers had reduced (between 1996-2001) their incidence of commuting beyond their own statistical subdivision (SSD) (of which there are 14 in the Sydney major statistical region). Earlier Yates (2005) also found only limited support for the notion that, in Sydney, structural change has resulted in re-urbanisation via increased reliance on new economy jobs in the inner city. She finds that with the exception of computing professionals, "Overall, however, there has been much greater growth in jobs in the locations where an increasing proportion of workers are living. In the case of Sydney, this is in the fringe regions of the city. The results for Sydney lend support to O'Connor and Healy's claims that jobs do follow people although care does need to be taken in drawing the implications about the direction of causality between growth in workplace and residential locations of workers." (2005:17).

Yates et al., (2006) however restrict their analysis to four key occupations referred to as 'indicator' occupations: computing professionals, nursing professionals, hospitality workers and cleaners (based on the DEWR National and State Skill Shortage Lists). Overall the author's find that: those who work in these high cost job rich inner city regions tend to commute from nearby regions; and secondly the inner city areas themselves have attracted increasing proportions of the local workforces to live there, especially nurses and computing professionals. Yates et al., (2006:x) conclude "there is little direct evidence to support the claims of those who express concerns that employers in high cost areas such as the inner city cannot attract key workers because of housing affordability problems." Housing affordability issues are likely to be greater for private sector workers in hospitality and workers than public sector workers like teachers, nurses and police officers (Yates et al., 2006). Moreover occupational factors are perhaps likely to less significant in explaining where people locate than socio-demographic factors, with young mobile 
workers preferencing inner-city living and providing an itinerant workforce for those low-wage service sectors where housing affordability may otherwise be an issue.

However even if they are not directly related to labour market shortages, worsening housing affordability may be generating a range of critical issues associated with poorer employment accessibility and longer commutes and the impacts may be different for different occupations. As Yates (2005:10) note "..the final and most difficult conceptual issue [arises] from the inherent difficulty in determining the impact of housing costs on labour market shortages. This cannot be determined solely from affordability measures because lower income workers who work in high cost areas might simply undertake longer commutes from areas where housing is more affordable. Consequently, the analysis of their housing cost or affordability position per se may show relatively little to be concerned about. The downside however is increasing commuting costs, social stress and poor traffic and environmental outcomes, rather than labour market shortages." Flood and Barbato (2005:vii) argue that commuting has three negative impacts on people's lives: impacting on their psychological and emotional well-being, impacting on people's relationships and interaction with their families, neighbourhoods, communities and workplaces and finally impacting on their physical and social environment.

Recently, Dodson and Sipe (2006) have shown that rising petrol prices may be impacting severely on those with poor employment and service accessibility in the outer suburbs and city fringe. For low income households the increasing cost of longer commutes, associated with higher petrol prices, is likely to impact further on already constrained household budgets. Examining data from the 2002 wave of the Survey of Household Income and Labour Dynamics Australia (HILDA), Flood and Barbato (2005) conclude the two occupational groups with the longest commuting times to and from work, are tradespeople and managers and administrators (where survey respondents were asked to report commuting times in hours). People in Sydney faced the longest average commuting times of employees in the country, with the longest being four hours and forty-three minutes per week (p.12). As Pocock and Mastermann-Smith (2006:7) note, "issues of commuting are very important to household welfare", and a dual earner household in Sydney lost nine and a half hours per week to commuting in 2002 (Flood and Barbato, 2005). Moreover as Flood and Barbato, (2005:29) indicate, one in five men working fulltime with children under 15 years spent more time commuting than they did with their children in 2002. Longer commuting times were also associated with less time being spent socialising with family and friends and participating in sports and community groups.

While such trends are worrying, is job-proximity the central issue in long and burdensome commuting times? Given that a wide range of factors influence residential location relative to work $^{1}$ - we examine occupational variations in commuting and ask what component of commuting is necessitated by the location of work given location of residence and what component of commuting might be considered volitional or related to factors other than simple job proximity?

\section{Data and Methodology}

We have obtained a custom release of Journey to Work data taken from the ABS Census of Population and Housing. It provides counts of commuters by 2-digit ASCO occupations for destination and origin Statistical Local Areas (SLAs) within NSW, Queensland and Victoria in 2001. Cross border commutes were also provided for Queensland and NSW and for Victoria and NSW. The coding of work destination zones is based on the address of the person's usual workplace. Destination zones are designed by state and territory based transport authorities and are devised to analyse planning and analysis of urban transport patterns and systems (ABS, 2002). Destination Zones aggregate to Statistical Local Area (SLAs), the unit used in this analysis.

Our distance calculations use the Euclidean distance between centroids of the SLA origin and destination, which captures distance as the 'crow flies'. These calculations are unlikely to give an accurate measure of actual distances commuted within Australian cities given that road networks, time of travel (related to congestion) and mode of transport may cause significant variation in distance and speed of travel. However Charron (2007:8) defends the use of Euclidean distance as the correct metric on technical and theoretical grounds, despite these shortcomings. The dynamic nature of the metropolitan system is

\footnotetext{
${ }^{1}$ Analysis of recent HILDA data reveals that housing and personal reasons out rank work-related factors in determining whether people move (Bill and Mitchell, 2006)
} 
alleged to proscribe the use of time. Recorded travel times reflect the efficiency of the transportation system and, in particular, its capacity to counter congestion. Charron claims that Euclidean distance is a static, theoretically neutral measure of distance. Also he notes that collection of these data is not reliant on costly network analysis.

Two approaches to the exploration of commuting patterns and the operation of spatial labour markets are relevant to our research. First we use a technique developed by Coombes et al (1985) to identify so called local labour markets via the grouping of areas. Second, we solve the Transportation Problem to compute a number of summary measures of commutes by occupation. We outline these techniques below and then explore their conceptual and empirical relevance to the study.

\section{Commuting Areas}

Any discussion of the constraints workers may face in accessing employment necessitates some understanding of the local labour market - that is the spatial dimensions of the search for employees by employers and the spatial dimensions of search for jobs by workers and the extent to which they overlap. While the ABS disseminates its Labour Force Survey (LFS) using labour force regions, these are largely based on labour force size with some reference to population homogeneity (ABS, 2004). If these areas do not in fact represent inherently meaningful units in an economic sense (i.e. conform to theoretical notions of local labour markets), the interpretation of these data is compromised, due to the presence of the Modifiable Areal Unit Problem (MAUP). The MAUP is present in all spatially aggregated data, and involves scale (the size of groupings) and aggregation or zoning effects (the particular way units are grouped). The implications of the MAUP are that the results are not necessarily independent of the units being used, and researchers need to be cautious in considering whether the unit is meaningful or appropriate to the question being asked, whether results may vary across units, and if so why. In the policy context, if a labour force area is defined too narrowly - labour market policy implemented by one local administration may impact on other administrative areas (Andersen, 2002:834). Alternatively if labour market policy is spatially localised in its impact, but the problem and its causes are widely distributed, policy may need to be implemented in adjoining local administrations.

Coombes (2002:1503) identifies three approaches to the creation of regions through spatial groupings, namely clustering, hierarchical and rules-based, but there are others, including boundary analysis. Cluster analysis progresses from the initial set of areas to the final set of regions in one step, drawing on the relative similarity of the statistical properties of the areas, as measured by an affinity matrix. Coombes also points out that clustering approaches usually specify the required number of regions at the outset, but such an approach cannot ensure that all regions will meet the minimum statistical objectives. This constraint, plus the requirement of contiguity, reduces the options that are available, so the resulting grouping is likely to be sub-optimal.

One form of spatial aggregation, which has been used to overcome the deficiencies of administratively defined areas, is based on the concept of Travel to Work Areas (TTWAs). UK researchers define a TTWA as a geographical area within which a high percentage of commuting by residents occurs. It is the site for the interplay between labour supply and demand and, in principle, should be the appropriate area over which labour market statistics can be defined (Coombes, 2002:1). These spatial markets result from both costs of mobility between jobs and the limitations of information networks (Hasluck, 1983). Employers and workers within a TTWA are assumed to be well informed and able to respond quickly to changes in market conditions. So each TTWA is considered to be largely self-contained (closed) from the rest of the economy, even though some commuting flows do cross boundaries.

Using measures of closure and interaction based on commuting patterns, Coombes et al (1986) developed an algorithm to identify TTWAs based on UK Census data. Watts (2004) discusses the algorithm in some detail. In summary, initially base spatial units are constructed (usually in the most disaggregated form at which the spatial data is available). Second, the researcher identifies spatial units with high levels of self-containment, in terms of job-ratio and supply-side self containment. Third, foci that display a high interaction/inadequate self containment are amalgamated. Fourth, these early 'commuting areas' (CAs) are expanded by grouping with other foci and non-foci with whom they have high levels of interaction. Then remaining residual non-focus SLAs are allocated to the CAs. Based on a minimum selfcontainment CAs are then iteratively dismembered and reallocated to corresponding CAs until all areas are absorbed (Watts, 2004:467). 
The algorithm has been adopted with some amendments in a number of recent international studies, including Spain (Casado-Diaz, 2000), New Zealand (Papps and Newell, 2002), Denmark (Andersen, 2002), USA (Tolbert and Sizer, 1996), in addition to Britain (Coombes et al, 1997), and also New South Wales (Watts, 2004). Across this literature different terminology has been employed to identify these areas. For example, Andersen (2002) uses the term Commuting Area, whereas Casado-Diaz (2000) refers to Local Labour Market Areas, Papps and Newell (2002) Functional Labour Market Areas and Tolbert and Sizer (1996) Commuting Zones. We adopt the term Commuting Areas (CAs) ${ }^{2}$ which adequately identifies the source of the disaggregation and is agnostic about its economic significance. Work by Watts (2004) has applied this technique to examine local labour markets in Australia using 2001 data. His findings indicated that the spatial classification employed by the ABS did not accord with commuting patterns developed, while the Bureau of Transport and Rural Economics classification (BTRE) appeared to provide a reasonable match.

\section{Excess Commuting}

The early research on commuting behaviour assumed a monocentric urban area, but the pattern of commuting was inconsistent with this underlying premise, since high rates of excess commuting were found (Hamilton, 1982). White (1988) dropped the assumption of monocentricity and took explicit account of the spatial location of workers and jobs. She developed a linear programming problem to determine the pattern of commuting flows across areas within an urban conurbation which yielded the system wide minimum average commuting costs (based on distance, time or both reflecting the total direct and indirect costs of commuting), given the spatial distribution of workers and jobs (see also Giuliano and Small, 1993; Horner and Murray, 2002; and Horner 2002).

The so called Transportation Problem (TP) can be specified as the choice of a Journey to Work (JTW) matrix [yij], where yij denotes the number of trips between residence $i$ and job location $j$, which minimises the overall cost of commuting, subject to the solution satisfying the row sum (resident employees) and column sum (local employment) constraints imposed by the actual JTW matrix, [xij].

If the actual average commuting cost (distance) were denoted as $\mathrm{Ta}$, with a corresponding minimum value of $\mathrm{TT}$, then the rate of excess commuting, $Z$ would be defined as:

$Z=(T a-T T) / T a$

White (1988) found little excess commuting. Using a fine disaggregation of origin and destination zones, Giuliano and Small (1993) found the rate of excess in-commuting for five county Los Angeles regions to be about two thirds, which challenged the minimisation model. However commuting patterns are likely to reflect variations in household characteristics, preferences and local amenities, as well as housing costs (Giuliano and Small, 1993:1485-1486). In addition, unless land markets operate in a manner consistent with the location model, commuting cost minimisation will not yield the same pattern of commuting (Chen, 2000:164).

Horner (2002) argues that the measure of excess commuting needs to be put in perspective by the computation of a maximum average commute which is obtained by respecifying the TP as a maximising, rather than a minimising, problem. A region may have a relatively high rate of excess commuting, as represented by (1), but the relative rate of excess commuting may be relatively low, as measured by (Ta$\mathrm{TT}) /(\mathrm{Tm}-\mathrm{TT})$, where $\mathrm{Tm}$ denotes the maximum commute. The maximisation and minimisation solutions form the limits of 'commuting capacity' supported by the urban form (Charron, 2007:4).

Yang (2005) uses an alternative pattern of commuting as a benchmark for the actual commute, namely Proportionately Matched Commuting (PMC). It is based on the premise that all workers compete equally for all jobs within the region, irrespective of the distance between residence and work, so commuting is essentially random. The expected number of workers who commute from zone $i$ to zone $j$ is given by

\footnotetext{
${ }^{2}$ We argue against the term Functional Economic Area because it prejudges the economic significance of this form of spatial disaggregation. The origin of the term Local Labour Market (LLM) lies in the identification of the labour catchment area for a large employer or a spatial cluster of smaller establishments (Morrison, 1990:510-511), so it too is inappropriate.
} 
where $\mathrm{W}$ denotes total commutes (employment) and $\bar{x}_{i,}, \bar{x}_{. j}$ respectively denote total number of residents in location $\mathrm{i}$ who are employed and total employment in location $\mathrm{j}$. The resulting JTW matrix of estimated flows satisfies the column and row constraints.

\section{Urban Form and Commuting}

Debates such as the 'key worker' debate and more generally the spatial mismatch hypothesis, argue that the spatial distribution of housing and jobs is more polarised for some key public sector occupations or certain demographic/social groups. These revolve around questions of changing urban form. However urban form is generally understood in an abstract context. In this dimension it is narrowly defined as the overall distribution of housing and jobs. In contrast to many empirical studies of (excess) urban commuting, it is essential to differentiate between occupations and or income groups, when investigating such theories.

These hypotheses are not simple to explore, however, because of the difficulty in separating the discretionary component of commuting from constraints on patterns of commuting arising from housing affordability. Charron (2007:2) argues that commuting consists of two main components, namely a morphological and a behavioral component. The morphological component is associated with urban form that is the underlying spatial imbalance between housing and jobs. By definition, this component forces workers to commute. Within the excess commuting framework, the globally optimal commute (across a reasonably self-contained area) is represented by the minimum commute solution to the TP. Thus Charron argues (p.2) that the difference between the actual commute and the minimum commute represents the behavioural component of commuting. The latter reflects individual characteristics and is based on tolerating the inconvenience of (additional) commuting in order to benefit from indirect rewards, which are primarily a broader range of residential and employment choices.

Here urban form is treated as exogenous, notwithstanding the fact that it is confined to the residential locations of the employed (and their work locations), which is the aggregate outcome of residential decisions made by the employed and those not working which necessarily have a discretionary component.

In addition, to treat the spatial distribution of housing and jobs of say professionals as in some sense exogenous to professional workers is problematic, since it is the outcome of thousands of interdependent decisions made by the employed (across all occupations) and the non-employed.

The alternative is to explore the 'key worker' hypothesis simply by documenting summary statistics based on actual commuting behaviour, ignoring any distinction between the morphological and behavioural components. It has been documented that the higher skilled tend to have longer commutes (Simpson, 1992 , Giuliano and Small, 1993) which may reflect the associated urban form, and specifically the larger local labour market, but could also reflect the discretionary component of commuting, reflecting a range of socio-economic characteristics, as briefly described at the beginning of the paper.. Thus simple crosssection comparisons of average distance commuted will not be very insightful in identifying whether certain workers are being forced to commute further.

Thus, while acknowledging that the urban form as represented by the spatial distribution of housing and jobs cannot be viewed as exogenous, we argue that exploring the cross-sectional variation of the minimum commute by occupation reduces part of the discretionary component of commuting behaviour and provides some insight as to whether workers in certain occupations are being required to commute further, due to problems of housing affordability.

However it can be argued that the comparison of minimum commutes is biased by the different spatial distributions of employment by occupation. Consequently we also generate summary statistics after normalising the spatial distribution of employment across each occupation. This is achieved by using the column sums corresponding to the aggregate JTW matrix representing the summed commuting flows across the 9 occupations. The elements of each column of the occupational JTW matrices were uniformly adjusted to bring their respective column sums into equality with the corresponding column sum for the 
aggregate flows matrix. ${ }^{3}$ Thus the column sums for each normalized occupation JTW matrix coincides with the column sums for the aggregated matrix, but the row sums for the occupation JTW matrices will differ from the corresponding row sums for the aggregated JTW matrix. Given that the problem is linear, we do not need to worry about scale, so that a uniform adjustment of all matrix entries will leave the solution effectively unchanged, given that our focus is average commutes. By anchoring the distribution of employment destinations, the comparison of minimum commutes by occupation then abstracts from the different distributions of employment location by occupation and solely reflects disparate distributions of residential locations by occupation.

In the light of the above, we adopt the following analytic techniques in this paper. First, adopting uniform parameter values, the Coombes algorithm is applied across 1320 Australian SLAs based on aggregate commuting data for which the occupation of employment is known. (Details available on request). The objective is to identify a common, geographical area in each state capital which is relatively self-contained with respect to commuting flows. This will enable a meaningful comparison of commuting patterns by occupation. The algorithm yields 241 CAs across the country. Urban CAs corresponding to Sydney, Melbourne and Brisbane were identified consisting of 52, 80 and 230 SLAs respectively. They exhibit high rates of overall self containment by residence and employment (0.990 and 0.989, Sydney; 0.991 and 0.983 , Melbourne; and 0.964 and 0.964 , Brisbane). ${ }^{4}$ We calculate a range of summary statistics associated with each CA, including rates of self containment averaged over the SLAs. We estimate actual, minimum and maximum commutes for the three urban areas for each of the nine ASCO2 major occupations - the last two summary statistics being the solutions to the TP. Adopting Charron's methodology, the urban form corresponding to each occupation is proxied by the minimum commute, so that the comparison of minimum commutes casts light on differential commuting patterns across occupations. We then normalise the occupational JTWs by the uniform adjustment of the elements of each column of each JTW matrix to neutralise the impact of unequal distributions of employment destinations.

\section{Results}

\section{Descriptive Analysis \\ Average Commutes}

Following the Coombes' methodology Commuting Areas (CAs) were devised using commuting flow data in 2001 for Sydney, Melbourne and Brisbane. These spatial areas (see maps in Bill, Mitchell and Watts, 2007, Appendix B) are the geography used for reporting results for the three cities in this section. Notably local labour markets comprise the whole of the metropolitan area in each of the cities. The weighted average of the distances between centroid of origin and centroid of destination was then computed for residents in these CA and results are reported by occupation in Tables 1 to 3 .

Looking at Table 1 below we find little variation in average commutes for low skilled and high skilled workers and low skilled workers (Elementary Clerical, Sales and Service workers, along with Labourers appear to have lower commutes). Distances commuted tend to be slightly higher in Sydney and Brisbane compared to Melbourne.

Further analysis of average distance commuted for 2 digit occupations in 2001, for Sydney, Melbourne and Brisbane CAs was also undertaken (see Table A.1 in the Appendix A of Bill, Mitchell and Watts, 2007). Again there appears to be little variation in distance commuted via occupation. Across the three cities, thus there would seem to be little support for the notion that unskilled and elementary workers

\footnotetext{
${ }^{3}$ The normalisation introduces non-integer elements into the JTW matrices and a non-integer solution, but our focus here is the overall average commute, rather than the optimal JTW matrices by occupation.

${ }^{4}$ Using the Coombes algorithm, some preliminary analysis has been undertaken of CAs by occupation for Australia, with particular reference to the three urban areas. The Sydney urban grouping of about 50 SLAs would appear to be relatively robust across occupations, so that the city as a whole represents a single labour market. The one exception is among labourers where the metropolitan labour market is divided in the south at Wollondilly. Elementary clerical workers have a larger metropolitan commuting area compared to professionals, one that extends south incorporating Wollongong and Shellharbour. However overall formal analysis of occupational commuting areas suggests there is little spatial variation in local labour markets for low-skill and high-skill occupations, within the Sydney metropolitan region.
} 
(cleaners, labourers and related workers, factory labourers and elementary service workers) are facing longer commutes than high and medium skill workers. Also for those groups who have been specifically targeted as key workers (teachers, nurses and health service workers), commutes do not appear to be significantly above average, and in some instances are well below average.

Table 1 Sydney, Melbourne and Brisbane Commuting Areas, average commutes by occupation, 2001

\begin{tabular}{l|r|r|r}
\hline & Mean Sydney & Mean Melbourne & Mean \\
& CA & CA & 16.8 \\
\hline Managers and Administrators & 21.8 & 14.8 & 18.2 \\
Professionals & 20.0 & 16.0 & 15.7 \\
Associate Professionals & 21.4 & 17.2 & 17.2 \\
Tradespersons and Related Workers & 23.6 & 15.3 & 21.4 \\
Advanced Clerical, Sales and Service Workers & 20.4 & 15.5 & 15.1 \\
Intermediate Clerical, Sales and Service Workers & 21.2 & 16.2 \\
Intermediate Production and Transport Workers & 22.2 & 13.5 & 21.1 \\
Elementary Clerical, Sales and Service Workers & 18.9 & 14.9 & 14.8 \\
Labourers and Related Workers & 20.4 & 19.1 \\
\hline
\end{tabular}

Source: ABS, Occupation by Journey to Work (JTW), custom data from Census 2001.

\section{Employment Self-Containment Rates}

Self-Containment rates (defined as the proportion of local employed workforce employed within the local area) vary significantly across Sydney, Melbourne and Brisbane, see Table 2. The Sydney CA appears to have much higher levels of self-containment at the SLA level and Brisbane appears to have lower levels of self-containment, perhaps because the SLAs in Brisbane are uncharacteristically small. In Brisbane and Sydney, labourers and related workers have higher self containment ratios. In Melbourne there appears to be little variation in self-containment rates across occupations.

We break the occupational distribution down to the 2-digit level for Sydney, Melbourne and Brisbane, see (see Table A.2 in Appendix A of Bill, Mitchell and Watts, 2007). The results indicate similar trends to those displayed at the 1-digit level. In Sydney the highest levels of self containment are found amongst other labourers and related workers, Farmers and Farm Managers, Skilled Agricultural and Horticultural workers and Intermediate Service workers. The lowest levels of self-containment are found amongst specialist managers, Business and Information professionals, Professionals, Associate Professionals and Science, Engineering and Related Associate Professionals. Trends and very similar in Melbourne and Brisbane (although in Brisbane Labourers and related workers experience low levels of self-containment also). Once again some very low levels of self-containment are reported in Brisbane for certain occupations labourers and related workers, health professionals, intermediate production and transport workers and factory labourers, which may be function of this state's unusually small city SLAs. Overall the results would seem to support for findings of Yates (2005) and Yates et al., (2006), while low income and by virtue low skilled occupations would appear to be experiencing housing stress, this is not reflected in lower self-containment rates. Self-containment rates are in fact much lower for people employed in advanced business services, professionals and those in knowledge intensive industries. 
Table 2 Self containment rates (\%) by occupation, Sydney, Brisbane and Melbourne, 2001.

\begin{tabular}{l|c|c|c}
\hline & $\begin{array}{l}\text { Self } \\
\text { Containment } \\
\text { Ratio, } \\
\text { Sccupation }\end{array}$ & $\begin{array}{l}\text { Self } \\
\text { Containment } \\
\text { Ratio, } \\
\text { Melbourne CA }\end{array}$ & $\begin{array}{l}\text { Self } \\
\text { Containment } \\
\text { Ratio, } \\
\text { Brisbane CA }\end{array}$ \\
\hline Managers and Administrators & 24.1 & 19.9 & 16.9 \\
Professionals & 24.9 & 18.5 & 12.6 \\
Associate Professionals & 28.1 & 21.1 & 15.2 \\
Tradespersons and Related Workers & 33.5 & 25.9 & 17.2 \\
Advanced Clerical, Sales and Service Workers & 32.8 & 28.1 & 23.0 \\
Intermediate Clerical, Sales and Service Workers & 29.5 & 20.6 & 13.9 \\
Intermediate Production and Transport Workers & 32.0 & 23.3 & 14.5 \\
Elementary Clerical, Sales and Service Workers & 40.2 & 31.3 & 15.8 \\
Labourers and Related Workers & 69.0 & 29.9 & 30.9 \\
\hline
\end{tabular}

Source: ABS, Occupation by Journey to Work (JTW), custom data from Census 2001.

\section{Excess Commuting by Occupation}

The summary statistics based on average commutes ${ }^{5}$ derived from the solutions to the two TPs are shown in Tables 3 (un-normalised) and 4 (normalised). First, all the measures of average commutes are higher for the Sydney CA than Melbourne and Brisbane CAs. Second, the ratio of actual to random commutes (final column of each Table) for all CAs indicates that commuting patterns are affected by the distance commuted, which would be expected. Third, the average commute tends to be highest for Tradespersons and the higher skilled Associate Professional and Managerial occupations, followed by the medium skilled occupations, with Elementary Clerical, Sales and Service occupations having the lowest average commute. Professionals have a relatively low average commute. Fourth, looking at the nonnormalised commutes, there is no evidence that the minimum commutes are systematically higher for the low skilled occupations. The minimum commute, as explained in the Data and Methodology section, represents the underlying urban form. It calculates the region wide pattern of commuting which would result if workers were allocated to jobs corresponding to the pattern yielding the minimum average commute for each occupation. ${ }^{6}$ However Tradespersons and the higher skilled occupations, including Professionals, tend to be associated with higher rates of excess commuting, which is the component of commuting that is not determined simply by job proximity. This indicates greater freedom of choice for higher income workers with respect to residential location. Relative and absolute rates of excess commuting are quite highly correlated, so there is little additional insight gained from the calculation of the maximum commute.

Turning to the results based on the normalised employment destination data (Table 4), actual commutes are no longer systematically higher for the higher skilled occupations. In particular, Intermediate Production and Transport workers have relatively high average commutes. However the higher skilled occupations continue to have higher relative and absolute rates of excess commuting, which again reveals a relatively larger discretionary component of their total commute. This in turn leads to the interesting result that the minimum commute tends to be relatively higher for the lower skilled occupations. This result provides some support for the hypothesis that the underlying distribution of jobs and workers is associated with lower job proximity and higher commutes for low income workers, after correction for the disparate distributions of employment location across occupations.

\section{Conclusion}

The analysis of commuting patterns is complex and beset with difficulties of interpretation because commuting flows are the outcome of interdependent decisions about residence and employment made by members of households.7This paper has explored the conceptual issues surrounding the interpretation of commuting patterns and provides a preliminary investigation of occupational differences in commuting for the three most populated state capitals in Australia. The associated 'key worker' debate has gained increasing traction in Britain and the USA in the past few years, but, so far, does not have strong empirical

\footnotetext{
${ }^{5}$ Commutes in this analysis are restricted to those inside the relevant CA.

${ }^{6}$ It is possible that the actual average commute for a particular SLA to be lower than the average commute for that SLA which is part of the region wide optimal pattern of commuting.
} 
support in Australia. In part this reflects the fact that skill shortages and the peak of the housing boom occurred after 2001, when the Census data were collected. A more thorough analysis will be possible when the 2006 ABS JTW data become available later in 2007.

We have argued that while the conceptual distinction between the morphological and behavioural components of commuting is problematic, it does make sense to focus on the component of commuting based on the 'urban form' corresponding to the particular occupation, which at least removes the inefficient component of the average commute, given the associated spatial distribution of housing and jobs. Furthermore, any discussion of excess commutes ought to recognise that household location decisions are jointly determined by household members. Two-income households are now the norm, and these generate multi-stage commuting decisions, for instance one partner commutes short distances and the other(s) longer distances. Moreover, transport costs can be calculated not solely on journey to work, but also length and cost of journey for social, leisure, retail and perhaps medical purposes, although such data are not available from the Census. The fact that suburban costs of commuting for non-work purposes may be less than those borne by inner city dwellers, may explain the willingness of suburban residents to experience longer journeys to work, translating to higher rates of excess commuting observed here.

Our tentative conclusions are as follows.

1. We find little variation in the urban commuting area by occupation in Sydney. For nearly all occupations the commuting area or local labour market extends across the whole of metropolitan Sydney - suggesting that there are high levels of economic interaction (commuting flows) for all occupations across this entire region, such that it represents a single labour market. The exception is for labourers and related workers, for whom the labour market is truncated in the south at Wollondilly.

2. High skill workers (employed in advanced business services and knowledge intensive industries) have the lowest levels of self-containment in all three capital cities, with the exception of labourers and related workers in Brisbane, and there is little occupational variation in commutes.

3. Thus our descriptive work seems to lend support for Yates (2005) and Yates et al., (2006) who find little evidence that low-skill occupations have lower levels of employment accessibility.

4. In the light of the above results we turn to a more sophisticated exploration of the nature of commuting by occupation, and seek to tease out the component of commuting necessitated by urban structure and that component which might be considered volitional. The derived minimum commutes provide little support for the underlying hypothesis, but once the distribution of employment destinations is anchored by the normalisation process, some tentative support is provided for the argument that low skill workers face lower levels of employment accessibility, and hence longer average commutes, which has important implications for equity.

5. Thus formal analysis of commuting patterns for the employed indicates some degree of occupational variation in commuting, but not significant variation. However this does not rule out that changes in housing affordability and the urban form have generated longer commutes for lowskilled workers. Our results importantly highlight the need to separate out the job-related and volitional components of commuting, given that high-skill and by virtue high-income workers may be influenced by factors other than straight-forward job-proximity in choosing their residential location. This is illustrated by greater excess commutes observed for this group. It is likely that there is a significant trade-off emerging between commuting time and housing affordability, particularly for the low-skilled. Longer minimum commutes for low-skill workers are no doubt a reflection of the housing market and the manner in which increasing CBD house price gradients are borne out in longer and more expensive travel times for those in the outer suburbs and city fringe of Australia's major cities.

As noted earlier, it is questionable whether Charron's claim about the morphological and behavioural components of commuting can be substantiated particularly when disaggregating by occupations. If high quality income data by occupation were available through the Census, then the minimum commute corresponding to a particular occupation could take explicit account of housing affordability, rather than relying on occupational status, which ignores the presence of intra-occupational income inequality. 
Table 3: Commuting by occupation, Sydney, Melbourne and Brisbane CAs, 2001.

\begin{tabular}{|c|c|c|c|c|c|c|c|}
\hline & Actual & Random & Max & Min & Xcess & Rel Xcess & Actual/Rand \\
\hline & \multicolumn{7}{|c|}{ Sydney } \\
\hline Managers & 17.90 & 33.62 & 44.50 & 11.09 & 38.02 & 20.38 & 53.25 \\
\hline Professionals & 16.71 & 33.51 & 44.16 & 10.43 & 37.60 & 18.63 & 49.87 \\
\hline Associate Professionals & 17.47 & 37.14 & 49.39 & 11.86 & 32.11 & 14.95 & 47.05 \\
\hline $\begin{array}{l}\text { Tradespersons } \\
\text { Advanced Clerical, Sales }\end{array}$ & 18.34 & 41.70 & 56.18 & 12.25 & 33.21 & 13.86 & 43.97 \\
\hline $\begin{array}{l}\text { \& Service } \\
\text { Intermediate Clerical, }\end{array}$ & 17.05 & 36.71 & 48.92 & 13.00 & 23.73 & 11.26 & 46.43 \\
\hline $\begin{array}{l}\text { Sales \& Service } \\
\text { Intermediate Production \& }\end{array}$ & 17.38 & 37.45 & 50.19 & 12.56 & 27.78 & 12.83 & 46.43 \\
\hline $\begin{array}{l}\text { Transport } \\
\text { Elementary Clerical, }\end{array}$ & 17.39 & 39.37 & 52.65 & 11.68 & 32.83 & 13.93 & 44.17 \\
\hline Sales \& Service & 14.90 & 40.21 & 54.33 & 10.98 & 26.28 & 9.04 & 37.06 \\
\hline Labourer & 15.69 & 41.81 & 56.23 & 10.86 & 30.82 & 10.66 & 37.54 \\
\hline \multirow[t]{2}{*}{ TOTAL } & 17.03 & 37.65 & 50.59 & 11.45 & 32.79 & 14.27 & 45.24 \\
\hline & \multicolumn{7}{|c|}{ Melbourne } \\
\hline Managers & 14.06 & 25.48 & 33.96 & 7.55 & 46.29 & 24.66 & 55.20 \\
\hline Professionals & 12.58 & 22.23 & 29.38 & 6.55 & 47.95 & 26.43 & 56.59 \\
\hline Associate Professionals & 13.46 & 25.75 & 34.41 & 7.86 & 41.61 & 21.10 & 52.28 \\
\hline $\begin{array}{l}\text { Tradespersons } \\
\text { Advanced Clerical, Sales }\end{array}$ & 14.08 & 30.86 & 42.95 & 8.03 & 43.02 & 17.35 & 45.64 \\
\hline $\begin{array}{l}\text { \& Service } \\
\text { Intermediate Clerical, }\end{array}$ & 12.98 & 26.69 & 35.70 & 8.90 & 31.42 & 15.21 & 48.62 \\
\hline $\begin{array}{l}\text { Sales \& Service } \\
\text { Intermediate Production \& }\end{array}$ & 13.37 & 26.45 & 35.79 & 8.42 & 37.07 & 18.11 & 50.55 \\
\hline $\begin{array}{l}\text { Transport } \\
\text { Elementary Clerical, }\end{array}$ & 13.49 & 30.21 & 43.10 & 7.74 & 42.64 & 16.26 & 44.65 \\
\hline Sales \& Service & 10.96 & 28.09 & 38.53 & 6.86 & 37.46 & 12.96 & 39.02 \\
\hline Labourer & 12.08 & 30.80 & 43.39 & 7.02 & 41.91 & 13.93 & 39.23 \\
\hline \multirow[t]{2}{*}{ TOTAL } & 13.01 & 26.74 & 36.25 & 7.46 & 42.68 & 19.28 & 48.64 \\
\hline & \multicolumn{7}{|c|}{ Brisbane } \\
\hline Managers & 13.57 & 27.21 & 34.26 & 7.60 & 43.96 & 22.38 & 49.86 \\
\hline Professionals & 11.34 & 19.82 & 25.00 & 5.33 & 52.99 & 30.54 & 57.20 \\
\hline Associate Professionals & 12.19 & 23.27 & 29.79 & 6.84 & 43.84 & 23.28 & 52.37 \\
\hline $\begin{array}{l}\text { Tradespersons } \\
\text { Advanced Clerical, Sales }\end{array}$ & 13.82 & 28.06 & 37.61 & 7.26 & 47.46 & 21.61 & 49.23 \\
\hline $\begin{array}{l}\text { \& Service } \\
\text { Intermediate Clerical, }\end{array}$ & 11.07 & 22.88 & 29.13 & 7.52 & 32.07 & 16.42 & 48.36 \\
\hline $\begin{array}{l}\text { Sales \& Service } \\
\text { Intermediate Production \& }\end{array}$ & 12.01 & 23.77 & 30.82 & 7.21 & 39.95 & 20.32 & 50.53 \\
\hline $\begin{array}{l}\text { Transport } \\
\text { Elementary Clerical, }\end{array}$ & 13.87 & 28.33 & 38.35 & 7.87 & 43.22 & 19.67 & 48.94 \\
\hline Sales \& Service & 10.21 & 25.14 & 33.32 & 5.93 & 41.89 & 15.61 & 40.60 \\
\hline Labourer & 12.70 & 31.15 & 41.57 & 7.39 & 41.86 & 15.56 & 40.78 \\
\hline TOTAL & 12.18 & 24.80 & 32.18 & 6.64 & 45.45 & 21.67 & 49.10 \\
\hline
\end{tabular}

Source ABS, Occupation by Journey to Work (JTW), custom data from Census 2001 
Table 4: Normalised Commuting by Occupation, Sydney, Melbourne and Brisbane CAs, 2001.

\begin{tabular}{|c|c|c|c|c|c|c|c|}
\hline & Actual & Random & Max & Min & Xcess & $\begin{array}{c}\text { Rel } \\
\text { Xcess }\end{array}$ & Actual/Rand \\
\hline & \multicolumn{7}{|c|}{ Sydney } \\
\hline $\begin{array}{l}\text { Managers } \\
\text { Professionals }\end{array}$ & $\begin{array}{l}18.23 \\
17.18\end{array}$ & $\begin{array}{l}37.66 \\
37.02\end{array}$ & $\begin{array}{l}50.46 \\
49.56\end{array}$ & $\begin{array}{l}10.98 \\
10.28\end{array}$ & $\begin{array}{l}39.77 \\
40.15\end{array}$ & $\begin{array}{l}18.36 \\
17.56\end{array}$ & $\begin{array}{l}48.40 \\
46.40\end{array}$ \\
\hline Associate Professionals & 17.53 & 37.85 & 50.84 & 11.59 & 33.93 & 15.15 & 46.33 \\
\hline $\begin{array}{l}\text { Tradespersons } \\
\text { Advanced Clerical, Sales \& }\end{array}$ & 18.89 & 38.59 & 51.64 & 13.23 & 29.97 & 14.74 & 48.96 \\
\hline $\begin{array}{l}\text { Service } \\
\text { Intermediate Clerical, Sales }\end{array}$ & 16.30 & 37.98 & & 17.24 & -5.73 & 5.42 & 42.92 \\
\hline $\begin{array}{l}\text { \& Service } \\
\text { Intermediate Production \& }\end{array}$ & 17.30 & 38.12 & 51.19 & 12.44 & 28.11 & 12.55 & 45.38 \\
\hline $\begin{array}{l}\text { Transport } \\
\text { Elementary Clerical, Sales \& }\end{array}$ & 18.33 & 38.48 & 51.47 & 13.25 & 27.72 & 13.30 & 47.64 \\
\hline Service & 15.15 & 37.02 & 49.71 & 11.25 & 25.76 & 10.15 & 40.92 \\
\hline \multirow[t]{2}{*}{ Labourer } & 15.94 & 36.83 & 49.24 & 11.47 & 28.00 & 11.81 & 43.27 \\
\hline & \multicolumn{7}{|c|}{ Melbourne } \\
\hline Managers & 13.97 & 26.11 & 35.03 & 7.14 & 48.87 & 24.48 & 53.50 \\
\hline Professionals & 12.96 & 25.05 & 33.74 & 6.12 & 52.79 & 24.77 & 51.72 \\
\hline Associate Professionals & 13.51 & 26.70 & 36.14 & 7.51 & 44.37 & 20.93 & 50.58 \\
\hline $\begin{array}{l}\text { Tradespersons } \\
\text { Advanced Clerical, Sales \& }\end{array}$ & 14.77 & 28.43 & 38.70 & 9.35 & 36.74 & 18.49 & 51.96 \\
\hline $\begin{array}{l}\text { Service } \\
\text { Intermediate Clerical, Sales }\end{array}$ & 12.35 & 27.07 & 36.71 & 8.02 & 35.03 & 15.08 & 45.62 \\
\hline $\begin{array}{l}\text { \& Service } \\
\text { Intermediate Production \& }\end{array}$ & 13.29 & 27.39 & & & 100.00 & \#DIV/0! & 48.52 \\
\hline $\begin{array}{l}\text { Transport } \\
\text { Elementary Clerical, Sales \& }\end{array}$ & 14.35 & 28.55 & 38.92 & 9.28 & 35.36 & 17.12 & 50.25 \\
\hline Service & 11.36 & 26.72 & 36.37 & 7.31 & 35.68 & 13.95 & 42.53 \\
\hline \multirow[t]{2}{*}{ Labourer } & 12.37 & 27.30 & 37.33 & 7.86 & 36.42 & 15.28 & 45.30 \\
\hline & \multicolumn{7}{|c|}{ Brisbane } \\
\hline Managers & 12.27 & 24.31 & 31.39 & 6.15 & 49.86 & 24.23 & 50.46 \\
\hline Professionals & 12.16 & 22.84 & 29.51 & 4.93 & 59.48 & 29.41 & 53.23 \\
\hline Associate Professionals & 12.42 & 24.65 & 32.01 & 6.55 & 47.24 & 23.06 & 50.39 \\
\hline $\begin{array}{l}\text { Tradespersons } \\
\text { Advanced Clerical, Sales \& }\end{array}$ & 13.73 & 25.90 & 33.70 & 8.12 & 40.87 & 21.93 & 53.00 \\
\hline $\begin{array}{l}\text { Service } \\
\text { Intermediate Clerical, Sales }\end{array}$ & 10.98 & 24.82 & & & 100.00 & \#DIV/0! & 44.23 \\
\hline $\begin{array}{l}\text { \& Service } \\
\text { Intermediate Production \& }\end{array}$ & 12.26 & 25.10 & 32.66 & 7.14 & 41.74 & 20.06 & 48.85 \\
\hline $\begin{array}{l}\text { Transport } \\
\text { Elementary Clerical, Sales \& }\end{array}$ & 13.38 & 26.39 & 34.31 & 8.56 & 36.03 & 18.72 & 50.69 \\
\hline Service & 11.29 & 24.98 & 32.46 & 6.90 & 38.85 & 17.15 & 45.17 \\
\hline Labourer & 12.13 & 25.66 & 33.39 & 7.76 & 36.02 & 17.04 & 47.26 \\
\hline
\end{tabular}




\section{References}

ABS, (2002), Census of Population and Housing Fact Sheet: Journey to Work, Cat. No. 2970.0.55.021, Australian Bureau of Statistics.

ABS (2004), Feature Article - Labour Force Survey of Regions, Australian Labour Market Statistics (Cat No. 6105.0), July 2004, Canberra.

Andersen, A.K. (2002) 'Are Commuting Areas Relevant for the Delimitation of Administrative Regions in Denmark?', Regional Studies, 36(8), 833-844.

Baum, S. (1997), 'Sydney, Australia: A Global City? Testing the Social Polarisation Thesis', Urban Studies, 34, 1881-1901.

Berry, M. (2006), "Housing Affordability and the Economy: a review of labour market impacts and policy issues", Australian Housing and Urban Research Institute (AHURI), RMIT-NATSEM Research Centre.

Bill, A. and Mitchell, W.F. (2006), 'Great Expectations - Migration and Labour Market Outcomes in Australia', Working Paper 06-08, Centre of Full Employment and Equity (CofFEE), University of Newcastle.

Bill, A., Mitchell, W.F. and Watts, M.J. (2007) 'The Occupational Dimensions of Local Labour Markets in Australian Cities', Working Paper 07-03, Centre of Full Employment and Equity, University of Newcastle.

Blumenberg, E. (2004), 'En-Gendering Effective Planning: spatial mismatch, low-income women, and transportation policy', Journal of the American Planning Association, Summer, Vol. 70 (3), 269-281.

BTRE (2003) Focus on Regions No. 1: Industry Structure, Information Paper 49, Bureau of Transport and Regional Economics, Australian Government.

Casado-Diaz, J.M. (2000) 'Local Labour Market Areas in Spain', Regional Studies, 34(9), 843-856.

Charron, M. (2007), 'From excess commuting to commuting possibilities: more extension to the concept of excess commuting', Environment and Planning A, 39(5), 1238 - 1254.

Chen, H.P. (2000), 'Commuting and Land Use Patterns', Geographical and Environmental Modelling, $(4,2), 163-173$.

Coombes, M.G., Wymer, C., Charlton, M.E., Bailey, S., Stonehouse, A. and Openshaw, S. (1997) 'Review of Travel-to-Work Areas and Small Area Unemployment Rates', Labour Market Trends, 105 9-12.

Coombes, M. (2002) Travel to Work Areas and the 2001 Census', Report to the Office of National Statistics, March, Centre for Urban and Regional Development Studies.

Coombes, M.G. and Openshaw, S. (1986) 'The Use and definition of Travel-to-Work Areas in Great Britain: Some Comments', Regional Studies, 16, 141-149.

Department of Education, Science and Training (DEST), (2002) Nature and Causes of Skills Shortages reflections from the Commonwealth National Industry Skills Initiative Working Groups, Report commissioned by the Department of Employment and Workplace Relations and the National Centre for Vocational Education Research, November 2002.

Dodson, J. (2005), 'Is there a Spatial Mismatch Between Housing Affordability and Employment Opportunity in Melbourne', Australian Housing and Urban Research Institute (AHURI), AHURI Final Report No. 80, Urban Policy Program, Griffith University.

Dodson, J., Buchanan, N., Gleeson, B., and Sipe, N., (2006), 'Investigating the Social Dimensions of Transport Disadvantage-1. Towards New Concepts of Transport Disadvantage', Urban Policy and Research, Vol. 24, No. 4, 433-453.

Dodson, J. and Sipe, N. (2006), 'Shocking the Suburbs: Urban Location, Housing Debt and Oil Vulnerability in the Australian City', Urban Research Program, Griffith University, Research Paper 8, July.

Fainstein, S., Gordon, I. and Harloe, M. (1992), Divided Cities: New York and London in the Contemporary World, Blackwell, Oxford and Cambridge, MA.

Flood, M. and Barbato, C. (2005), 'Off to Work - Commuting in Australia', Discussion Paper Number 78, The Australia Institute, Canberra. 
Giuliano, G. and Small, K.A. (1993), 'Is the Journey to Work Explained by Urban Structure?', Urban Studies, 30, 1485-1500.

Gobillon, I., Selod, H. and Zenou, Y. (2003), "Spatial Mismatch: from hypothesis to the theories", Institute for the Study of Labor (IZA), IZA Discussion Paper No. 693,

http://papers.ssrn.com/sol3/papers.cfm?abstract_id=382787

Hamilton, B.W. (1982), 'Wasteful commuting', Journal of Political Economy, 90, 1035-1053.

Horner, M.W. (2002), 'Extensions to the Concept of Excess Commuting', Environment and Planning A, 34, 543-66.

Horner, M.W. and Murray, A.T. (2002), 'Excess Commuting and the Modifiable Areal Unit Problem', Urban Studies, 39(1), 131-139.

Houston, D., (2005), 'Employability, Skills Mismatch and Spatial Mismatch in Metropolitan Labour Markets', Urban Studies, Vol. 42 (2), 221-243.

Morrison, P.S. (1990) 'Segmentation theory applies to local, regional and spatial labour markets', Progress in Human Geography, 14(4): 488-528.

Nelson, B. (2004) A New Approach To Tackling Skills Shortages In Trades, Media Release, The Hon Dr Brendan Nelson, Minister for Education, Science and Training, 6 / 4 / 2004.

O'Connor and Healy (2002), The Links Between Labour Markets and Housing Markets in Melbourne, Australian Housing and Urban Research Institute, Melbourne.

Papps, K.L. and Newell, J.O. (2002) 'Identifying Functional Labour Market Areas in New Zealand: A Reconnaissance Study Using Travel-to-Work Data', IZA Discussion Paper 443.

Pocock, B. and Masterman-Smith, H., (2006), 'Work, Families and Affordable Housing', presented to the Dunstan Foundation Forum: 'Over our heads: Housing Costs and Australia's Future', 6 June 2006, National Wine Centre, Botanic Road, Adelaide.

Randolph, B. and Holloway, D. (2005), 'The Surburbanization of Disadvantage in Sydney: New Problems, New Policies', Opolis : An International Journal of Suburban and Metropolitan Studies, vol. 1, Issue 1, Article 6, 49-64.

Sassen, S. (1991) 'The Global City: New York, London, Tokyo', Princeton NJ L: Princeton University Press.

Shen, Q. (2001) 'A Spatial Analysis of Job Openings and Access in a US Metropolitan Area', Journal of the American Planning Association, 67(1), 53-68.

Simpson, W. (1992) Urban Structure and the Labour Market: Worker Mobility, Commuting and Unemployment in Cities, Oxford: Clarendon Press.

Tolbert, C.M. and Sizer, M. (1996) US Commuting Zones and Labor Market Areas: A 1990 Update, Department of Agriculture, Economic Research Service, Agricultural and Rural Economic Division, Washington, DC.

Watts, M. (2004), 'Local Labour Markets in New South Wales: fact or fiction?', Proceedings from A Future That Works: economics, employment and the environment, Carlson, E. (Ed), The University of Newcastle, Australia.

White, M.J. (1988), 'Urban Commuting Journeys are Not "Wasteful', Journal of Political Economy, 96, 1097-1110.

Yang, J. (2005), 'Commuting Aspects of Spatial Decentralization: A Comparison of Atlanta and Boston', Regional Analysis and Policy, 35(1), 69-78.

Yates, J., Randolph, B. and Holloway, D., (2006), 'Housing Affordability, Occupation and Location in Australian Cities and Regions', Australian Housing and Urban Research Institute (AHURI), Melbourne.

Yates, J., Randolph, B., Holloway, D. and Murray, D. (2006), Housing Affordability, Occupation and Location in Australian Cities and Regions, Final Report, Australian Housing and Urban Research Institute (AHURI), Melbourne. 
Yates, J. (2005), 'Are Occupational Choices Affecting Housing Choices?', Paper prepared for the Australian Social Policy Conference, 2005, 'Looking Back, Looking Forward - A Quarter of a Century of Social Change', University of New South Wales, 20-22 July 2005. 